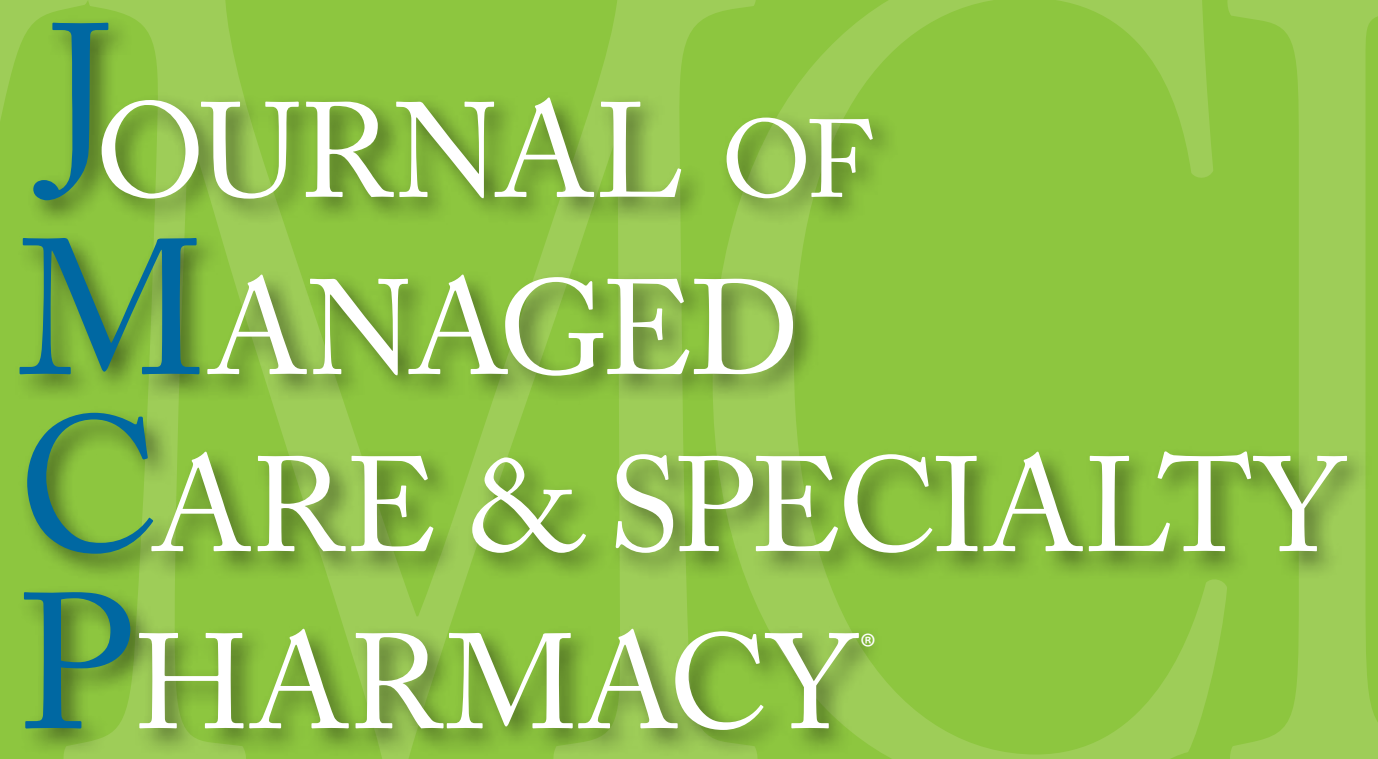

Supplement $\square$ Volume 22 a Number 9-a × September 2016

\title{
Biosimilars: Opportunities to Promote Optimization Through Payer and Provider Collaboration
}

Chronis H. Manolis, RPh; Kiran Rajasenan, MD; William Harwin, MD; Scott McClelland, RPh; Maria Lopes, MD; and Carolyn Farnum, BS 


\section{JMCP}

\section{Publisher}

Susan A. Cantrell, RPh, CAE

Chief Executive Officer

Academy of Managed Care Pharmacy

\section{Editor-in-Chief}

Laura E. Happe, PharmD, MPH

727.488.2700, lhappe@jmcp.org

\section{Assistant Editor}

Robert P. Navarro, PharmD

University of Florida College of Pharmacy

Gainesville, FL

\section{Assistant Editor}

Karen L. Rascati, PhD

University of Texas College of Pharmacy

Austin, TX

\section{Assistant Editor}

Karen M. Stockl, PharmD

OptumRx, Irvine, CA

Managing Editor

Jennifer A. Booker

703.317.0725, jmcpreview@amcp.org

\section{Production Editor}

Carol Blumentritt

602.616.7249, cblumentritt@amcp.org

\section{Graphic Designer}

Margie C. Hunter

703.297.9319, mhunter@amcp.org

\section{Account Manager}

Grant Menard, American Medical Communications, Inc. 267.614.6809, GMenard@americanmedicalcomm.com This supplement to the Journal of Managed Care \& Specialty Pharmacy (ISSN 1944-706X) is a publication of the Academy of Managed Care Pharmacy, 100 North Pitt St., Suite 400, Alexandria, VA 22314; 703.683.8416; 703.683.8417 (fax)

Copyright $\odot$ 2016, Academy of Managed Care Pharmacy. All rights reserved. No part of this publication may be reproduced or transmitted in any form or by any means, electronic or mechanical, with out written permission from the Academy of Managed Care Pharmacy.

POSTMASTER: Send address changes to JMCP

100 North Pitt St., Suite 400, Alexandria, VA 22314.

\section{Supplement Policy Statement}

\section{Standards for Supplements to the}

Journal of Managed Care \& Specialty Pharmacy

Supplements to the Journal of Managed Care \& Specialty Pharmacy (JMCP) are intended to support medical education and research in areas of clinical practice, health care quality improvement, or efficient administration and delivery of health benefits. The following standards are applied to all JMCP supplements to ensure quality and assist readers in evaluating potential bias and determining alternate explanations for findings and results.

1. Disclose the principal sources of funding in a manner that permits easy recognition by the reader.

2. Disclose the existence of all potential conflicts of interest among supplement contributors, including financial or personal bias.

3. Describe all drugs by generic name unless the use of the brand name is necessary to reduce the opportunity for confusion among readers.

4. Identify any off-label (unapproved) use by drug name and specific off-label indication.

5. Strive to report subjects of current interest to managed care pharmacists and other managed care professionals.

6. Seek and publish content that does not duplicate content in the Journal of Managed Care \& Specialty Pharmacy.

7. Subject all supplements to expert peer review.
Chronis H. Manolis, RPh, is Vice President of Pharmacy Services for UPMC Health Plan. In this role, he oversees the pharmacy programs for the health plan's Commercial, Medicare, Medical Assistance, Specialty Plan, Health Exchange, and Children's Health Insurance Program products. Manolis has responsibility for drug benefit design, clinical program development, formulary management, manufacturer rebate administration, clinical call center operations, and overall performance of the pharmacy services division.

Manolis holds a bachelor's degree in pharmacy from the University of Pittsburgh and has more than 30 years of experience in the pharmacy and managed care industry, including retail, mail order, specialty pharmacy, managed care, government programs, and account management/sales.

Manolis also serves as an Adjunct Instructor at the University of Pittsburgh School of Pharmacy and is a member of the National Committee on Quality Assurance (NCQA)/Health care Effectiveness Data and Information Set (HEDIS) Expert Pharmacy Panel.

Kiran Rajasenan, MD, is a Clinical Assistant Professor of Medicine at the University of Pittsburgh and has practiced in a large single specialty group for the last 16 years. He has been selected as a "Best Doctor" by Pittsburgh Magazine for the last 5 years and has twice received the Leo Creip Award for patient care from UPMC Cancer Centers. He has also served on the Board of Directors for the Allegheny County Chapter of the American Cancer Society and has previously served on the Board of Trustees for Gannon University. Rajasenan graduated with his medical degree from Hanemann University in 1996 and currently resides in Wexford, Pennsylvania, with his wife, Rose, and his 2 daughters, Lauren and Calli.

William Harwin, MD, founded Florida Cancer Specialists \& Research Institute (FCS) in 1984 and has guided the organization to become the largest independent oncology/hematology practice in the United States. An innovator and leader in the field of medical oncology/hematology, Harwin is a highly respected clinician, researcher, and medical administrator. He has a strong emotional connection to FCS and a never-ending drive to ensure that the company is best in class in every aspect of oncology and provides compassionate, state-of-the-art care with a focus on participation in clinical trials and physician education. He is board certified in internal medicine, medical oncology, and hematology and is a former President of Florida Society of Clinical Oncology (FLASCO). Each year for the past decade, Harwin has been named one of the top doctors in Southwest Florida by "Castle Connolly: America's Top Doctors." Winners of this prestigious award are peer-nominated and then reviewed and chosen by a national, physician-led panel, ensuring that the highest practice standards are achieved.

After receiving his bachelor's degree from Oberlin College and his medical degree from Baylor College of Medicine in Houston, Harwin completed his internship and residency in internal medicine and a fellowship in hematology and medical oncology at the University of Miami. In 1997, Harwin performed the first peripheral stem cell transplant in Lee County for a woman with breast cancer. He is a noted lecturer and has published in leading medical journals, including the prestigious Journal of Clinical Oncology. He currently serves on the Editorial Board for the Oncology Business Review (OBR). In 2015, Harwin was named to the Physician Advisory Panel for Florida Blue (Blue Cross/Blue Shield), one of the largest health insurance companies in the state.

Harwin has served as a principal investigator in numerous clinical trials throughout his career and has been the driving force in developing the Florida Cancer Specialists Phase 1 Clinical Trials Program, which has set a national benchmark for community oncology and rivals programs at many larger academic medical centers. FCS currently has 2 Drug Development Units in its network, and Harwin consistently leads the practice in the accrual of patients for clinical trials.

continued on page $S 2$ 


\title{
Table of Contents
}

\section{Biosimilars: Opportunities to Promote Optimization Through Payer and Provider Collaboration}

Chronis H. Manolis, RPh; Kiran Rajasenan, MD; William Harwin, MD;

Scott McClelland, RPh; Maria Lopes, MD; and Carolyn Farnum, BS

\author{
S3 Summary \\ S3 Challenges \\ S6 Potential Solutions \\ S8 Future Implications for Health Plans and Providers \\ S9 References
}

\section{Disclosures}

This supplement was funded by Pfizer. Manolis, Rajasenan, Harwin, and McClelland did not receive compensation for this supplement. Lopes and Farnum are full-time employees of CDMI/Magellan Rx. This supplement was developed by CDMI/Magellan Rx and funded by Hospira, which was acquired by Pfizer in September 2015.

The release date is September 1, 2016. 
Scott McClelland, PharmD, RPh, CHIE, is Vice President of Commercial and Specialty Pharmacy Programs for Florida Blue. In this position, he is responsible for leading the internal pharmacy team and for the oversight and development of the clinical and operational strategy for the traditional, specialty, and medical pharmacy areas to ensure that members have access to clinically sound and affordable pharmacy benefits and programs.

Before joining Florida Blue in 2006, McClelland held a leadership position within the HCA Hospital System as the Manager of Pharmacy Operations. He has over 20 years of experience as a clinical pharmacist specializing in critical care hospital-based medicine and pharmacy benefit management.

Throughout his career, McClelland has been active in community and professional organizations. He is a member of the Academy of Managed Care Pharmacy (AMCP), America's Health Insurance Plans (AHIP), and American Society of Health-System Pharmacists (ASHP) and has served as Adjunct Professor to several university systems. McClelland serves on the University of Georgia College of Pharmacy Dean's Advisory Board and as Chair of the Blue Cross and Blue Shield National Council of Physician Executives (NCPE) Association.

McClelland received his bachelor of science and doctorate of pharmacy degrees from the University of Georgia. In addition, he completed an ASHP pharmacy practice residency and received his Health Information Certification from the Blue Cross Blue Shield Association. McClelland graduated from the AHIP Executive Leadership Program through Kellogg Business School, focused on the health care industry.

Maria Lopes, MD, has been in the managed care industry for over 19 years. She is currently the Chief Medical Officer of Magellan Rx, former Chief Medical Officer (CMO) of GHI EmblemHealth, Chief Medical Director of Horizon Blue Cross Blue Shield of New Jersey and $\mathrm{CMO}$ of AMCHealth.

In her role at Magellan Rx, Lopes oversees clinical program development and implementation, formulary management, patient outreach and clinical assessment, pathway development, and strategic solutions across medical and pharmacy benefits for a variety of disease states (e.g., oncology, rheumatoid arthritis, multiple sclerosis, intravenous immunoglobulin, hereditary angioedema, HIV, hepatitis C, neurotoxins, Gaucher's, hemophilia, and pulmonary arterial hypertension). She works closely with over 40 health plans to bring customized and innovative solutions that add quantifiable clinical and economic value.

Lopes has extensive experience in disease and case management, employee health and wellness, and quality initiatives to improve HEDIS/Medicare star performance. She has been responsible for medical policy development and implementation, correct coding initiatives, fraud and abuse deterrence programs, physician profiling, and the development of a medical home pilot project in New York. Lopes has overseen medical and pharmacy utilization in a network and a staff model. She has worked closely with Geisinger Health Systems on innovative strategies in e-health, data analytics, and health information technology to improve patient engagement, coordinate care, and align incentives as part of Geisinger's ProvenHealth Navigator (Advanced Medical Home).

Lopes is an obstetrician and gynecologist. She has a bachelor's degree in biochemistry from Wesleyan University, received her medical degree from the University of Connecticut, and has a master's degree in administrative medicine from the University of Wisconsin.

Carolyn Farnum, BS, is a Senior Market Research Manager for Magellan Rx. She has consistently demonstrated her ability to effectively manage a variety of managed markets projects, including payer and provider insights generation, publication of consensus documents, and development of medical policy strategies. Farnum is also responsible for the planning, execution, and publication of best-practice consensus documents, all medical writing activities, and reimbursement and medical policy market research initiatives, as well as the day-to-day operation and content development for the Magellan Rx Report.

\section{Author Correspondence Information}

Carolyn Farnum, BS

Magellan Rx

130 Bellevue Ave, Ste 201, Newport, RI, 02840

Tel.: 401.344.1014; E-mail: cfarnum@magellanhealth.com 


\title{
Biosimilars: Opportunities to Promote Optimization Through Payer and Provider Collaboration
}

\author{
Chronis H. Manolis, RPh; Kiran Rajasenan, MD; William Harwin, MD; \\ Scott McClelland, RPh; Maria Lopes, MD; and Carolyn Farnum, BS
}

\begin{abstract}
SUMMARY
A panel was convened that consisted of 1 medical director, 2 pharmacy directors, and 2 oncologists, who represented the University of Pittsburgh Medical Center Health Plan, an integrated delivery network, and Florida Blue, a progressive regional health plan. This panel met in order to share ideas, discuss challenges, and develop practical solutions to promote optimal utilization in order to encourage collaboration between payers and providers to help ensure the success of biosimilar entrants into the marketplace. Live meetings were conducted in Orlando, Florida, and Pittsburgh, Pennsylvania, and were followed by virtual meetings to solidify ideas and concepts for this supplement. It is important for biosimilar manufacturers to identify potential payer, provider, and patient obstacles in order to develop strategic and tactical plans to preemptively address these potential obstacles. Gathering payer and provider insights will shed light on various issues such as access and reimbursement. Biosimilar manufacturers must be proactive in the education of payers, providers, and patients to ensure access to biosimilars.

A strong factor emphasized among this group was that the assumption surrounding biosimilar development and use is the potential for health care cost savings. According to the panel, payers and providers must carefully consider economic implications and potential cost-effectiveness in order to increase the acceptance or understanding of biosimilars in clinical practice. The group identified 3 major challenges surrounding biosimilar adoption: (1) provider confidence in biosimilar education and clinical value, (2) provider confidence in reimbursement for new biosimilars, and (3) creating shared payer and provider cost-savings. After identification of the 3 challenges, the group posed potential solutions to help with biosimilar adoption.
\end{abstract}

J Manag Care Spec Pharm. 2016;22(9-a):S3-S9

Copyright $\odot 2016$, Academy of Managed Care Pharmacy. All rights reserved.

$\mathrm{B}$ iosimilars create unique market dynamics that the United States health care system has not yet experienced. Biosimilars are not generics-these are not "just another brand" - and there are no reliable analogues that can be used to define best practices. European data are not an appropriate analogue, as the European and U.S. markets vary in significant aspects including access, pricing, and factors influencing utilization. The panel members felt that in Europe, the adoption of a biosimilar varies by country, cost, and use depending on site of care (SOC). As more biosimilars enter the market, important stakeholders within the health care industry will be tasked with making decisions surrounding the adoption of biosimilars. The panel members indicated that most biosimilars currently in development will fall under the medical benefit versus the pharmacy benefit, and payers need to prepare for this in the development of medical policies. The purpose of this publication, assuming a cost-savings opportunity is available, is to highlight potential collaborative opportunities between payers and providers that can help to optimize the economic value associated with near-term biosimilar products that will fall under the medical benefit.

In 2015, the first biosimilar was approved by the U.S. Food and Drug Administration (FDA) under the Biologics Price Competition and Innovation Act (BPCIA). Zarxio (filgrastimsndz), manufactured by Sandoz, is a biosimilar version of Neupogen (filgrastim), an injectable granulocyte colony-stimulating factor (G-CSF) manufactured by Amgen. It is important to note that filgrastim-sndz was approved for all 5 indications associated with filgrastim. ${ }^{1}$ When filgrastim-sndz was launched on September 3, 2015, there was much excitement and optimism among the health care community, as many had hoped that biosimilar products would help curb rising specialty drug costs and create additional competition within the U.S. market. An analysis by Express Scripts, a pharmacy benefit manager (PBM), estimated that filgrastim-sndz could save the U.S. health care system nearly $\$ 6$ billion over the next decade, ${ }^{2}$ assuming that filgrastim-sndz would be available at a $30 \%$ discount compared with filgrastim. ${ }^{3}$ However, filgrastimsndz launched with a wholesale acquisition cost (WAC) that was $15 \%$ below the WAC of filgrastim and only 3\% below the average sales price (ASP), which is the price most commonly used to reimburse physicians in the United States. ${ }^{4-6}$ Therefore, the cost of filgrastim-sndz does not provide a significant savings opportunity to U.S. payers. Unfortunately, from a managed care perspective, filgrastim-sndz is not a good example of how biosimilars can generate cost savings for payer organizations, but with dozens of biosimilars in the pharmaceutical pipeline, many more opportunities remain on the horizon.

\section{Challenges}

\section{Provider Confidence in Biosimilar Education} and Clinical Value

Lack of Awareness/Education. Payers and providers of the panel both felt there that needs to be more education pertaining to biosimilars, as some were not aware of biosimilars in general. Providers and payers have much experience with reference products; however, the shift to biosimilars will require a major educational component.

According to the panel, payers agreed that the biosimilar manufacturer must put a substantial amount of effort into educating all health care stakeholders about biosimilars. In addition, the panel stated that payers would be willing to supplement educational efforts if a significant savings opportunity was available, but the lack of payer resources makes widespread educational campaigns challenging in the absence of pharmaceutical company support. 
In general, if the FDA has approved the biosimilar product, most providers will be accepting of the biosimilar's equivalency to the reference product. However, the panel felt that there will still be a few providers who will remain cautious, requiring additional assurance that biosimilars are safe and effective, by evaluating the evidence from the clinical trials and real-life outcomes, especially for indications where clinical trial data are lacking. The panel felt that, as with all products, providers must be vigilant when they prescribe biosimilars and truly ensure there are no clinically meaningful differences in safety and efficacy.

It is also critical that patients are educated and accepting of the prescribed biologic. The panel advised that providers might not have the time or resources to fully educate the patient, and portions of the educational component may be more efficiently delivered with assistance of the health plan and manufacturer. If patients use the product, patient support programs from the biosimilar manufacturer need to be just as good, if not better, than those support programs offered by the reference product manufacturer. According to the panel members, since these drugs will most likely be placed on high-tiered formularies, biosimilar manufacturers will need to provide comparable financial assistance for patients, similar to that provided by reference product manufacturers.

Lack of Understanding of Biosimilar Clinical Value. Although there is a range of regulatory definitions that exist for biosimilars, biosimilars are a biological compound that is highly similar to the reference product, with no clinically meaningful differences in safety, purity, and potency. Biosimilars cannot be identical to the reference product due to the complex manufacturing process in which they are produced using living cells via a multi-step process, in contrast to small-molecule drugs that are manufactured through chemical synthesis. Due to the manufacturing process associated with biosimilars, payers and providers want assurance that every time a biosimilar product is used, it will not have any clinically meaningful differences versus the reference product.

Health plans and providers agree that there is an educational deficit regarding biosimilars. QuantiaMD conducted a survey that included approximately 300 primary care physicians and specialists, including endocrinologists, gastroenterologists, hematologists, infectious disease specialists, oncologists, nephrologists, neurologists, and rheumatologists, and found that physicians believe biosimilars will provide value to health care. ${ }^{7}$ However, specialists who currently prescribe biologics (that potential biosimilars are seeking approval of) generally lack the awareness and education needed to provide strong support of biosimilars. ${ }^{7}$ The QuantiaMD report also found the following?:
1. Ninety-four percent of physicians believe biosimilars will provide value to the health care system.

a. The top value cited is "lower costs to patients/the health system" (35\%), followed by "greater patient access to therapies" (30\%) and "increased choice among prescribing options" (27\%).

2. Seventeen percent of prescribing specialists stated that they are "very likely" to prescribe biosimilars to eligible patients, while $70 \%$ of prescribing specialists indicated that they either "aren't sure" or are "somewhat likely" to prescribe a biosimilar. 13\% stated that they are "not very likely" or "not at all likely" to prescribe biosimilars.

3. Specialty societies were the prescribing specialists' most trusted source of information pertaining to biosimilars (25\%), followed by peers (19\%) and key opinion leaders (KOLs; 18\%). These sources-and FDA approval-are among the top trusted sources in learning about biosimilars.

Lack of Clinical Evidence: Extrapolation. Extrapolation is the approval of a biosimilar for use in an indication held by the reference product not directly studied in a comparative clinical trial with the biosimilar. Payers and providers report that there will be a problem if not all indications of the reference product are extrapolated to the biosimilar product in the absence of clear clinical trial evidence to support each indication. The decision of whether or not to accept extrapolated indications will have a major impact on the management and adoption of biosimilars within payer organizations and the ability to optimize the savings potential associated with these new products.

\section{Provider Confidence in Reimbursement for New Biosimilars}

Providers mentioned that there is a lack of education and understanding surrounding reimbursement for biosimilars, a topic that providers find confusing. In the United States, physicians generally have greater freedom over product choice; however, for products that would be covered under the Medicare Part B benefit, the standard reimbursement formula for a biosimilar drug will be based on the biosimilar ASP plus $6 \%$ of the ASP of the reference product, a strategy designed to remove incentives to use one product over another. ${ }^{8}$ However, due to the budget sequester in 2012, it was mandated by the Centers for Medicare \& Medicaid Services (CMS) to decrease Part B drug reimbursement by $2 \% .{ }^{4}$ As a result of this decision, providers are now reimbursed for oncolytics at ASP plus $4.3 \%{ }^{4}$ In February 2014, this was re-evaluated, and the sequester cuts were extended through $2024 .{ }^{4}$

It is also important to consider that there is only a $3.8 \%$ difference between the ASP of filgrastim-sndz and filgrastim per Q1 2016 prices, delineated in Table 1.

Policy, Billing, and Coding Uncertainties. Payers still have questions surrounding how to develop medical policies so that providers feel comfortable with the biosimilar reimbursement process. 


\begin{tabular}{l|c|c|c}
\hline TABLE 1 & \multicolumn{4}{l}{$\begin{array}{l}\text { Filgrastim-sndz ASP Versus Filgrastim } \\
\text { ASP per Dose }\end{array}$} \\
\hline Drug & Strength & WAC & ASP \\
\hline Filgrastim-sndz & $300 \mathrm{mcg} / 0.5 \mathrm{~mL}$ & $\$ 275.66$ & $\$ 274.24$ \\
& $480 \mathrm{mcg} / 0.8 \mathrm{~mL}$ & $\$ 438.98$ & $\$ 438.79$ \\
\hline Filgrastim & $300 \mathrm{mcg} / 0.5 \mathrm{~mL}$ & $\$ 324.30$ & $\$ 285.00$ \\
& $480 \mathrm{mcg} / 0.8 \mathrm{~mL}$ & $\$ 516.45$ & $\$ 456.00$ \\
\hline Percentage of difference & $300 \mathrm{mcg} / 0.5 \mathrm{~mL}$ & $15 \%$ & $3.8 \%$ \\
& $480 \mathrm{mcg} / 0.8 \mathrm{~mL}$ & $15 \%$ & $3.8 \%$ \\
\hline
\end{tabular}

According to CMS, biosimilars for the reference product will all share the same Health care Common Procedure Coding System (HCPCS) code, with the reference product retaining a unique code. ${ }^{9}$ When providers submit a claim for a biosimilar, they will be required to include a modifier that identifies the manufacturer of the biosimilar and will allow payers to identify specific biosimilar products in claims data. CMS may issue HCPCS codes for biosimilars and assign corresponding modifiers. However, if the HCPCS code and modifier do not appear on CMS's quarterly update notifying providers of billing and coding changes, then it is not required to utilize a modifier. In addition, if there is not a HCPCS code that can adequately describe biosimilars as they enter the market, providers can bill using a miscellaneous or "not otherwise classified" code. In this case, when a miscellaneous code is used, a manufacturer modifier is not required. Lastly, the determination of a reimbursement amount for a biosimilar is not affected by the use of a modifier. ${ }^{9}$ Table 2 shows the example for filgrastim-sndz.

Although providers and health plans both feel that billing with the appropriate HCPCS code and modifier for a biosimilar is helpful, there are still some gray areas. Firstly, there could be an educational deficit among the provider's office staff when billing, as they might not be aware that billing with a modifier should be used when applicable. It could also be looked at as tedious, as this is another step required when submitting a claim. The panel advised that the addition of the modifier is helpful for CMS to track claims and in the development of a better understanding pertaining to the utilization of specific biosimilar products when billed correctly. The panel also expressed that the addition of the modifier could be helpful for the provider when tracking adverse events associated with a product. However, a problem may arise in which a biosimilar product does not have a HCPCS code or modifier and the provider has to bill with a miscellaneous code, which could delay time to reimbursement and potentially place providers at financial risk. Should this occur, this could be detrimental to biosimilar adoption, as any claim rejections or delayed time to reimbursement could create reluctance among providers to prescribe biosimilars. While this may seem simple with the addition of a single biosimilar approval, the addition of more modifiers is expected to complicate billing procedures as more

\section{TABLE 2 Example of Billing and Coding} for Filgrastim-sndz 9

\begin{tabular}{l|c|c}
\hline Biosimilar HCPCS Code & Product Name & $\begin{array}{c}\text { Corresponding } \\
\text { Required Modifier }\end{array}$ \\
\hline $\begin{array}{l}\text { Q5101 Injection, Filgrastim (G-CSF), } \\
\text { Biosimilar, 1 microgram }\end{array}$ & Zarxio & ZA-Novartis/Sandoz \\
\hline $\begin{array}{l}\text { HCPCS = Healthcare Common Procedure Coding System; G-CSF = granulocyte } \\
\text { colony-stimulating factor. }\end{array}$
\end{tabular}

biosimilars are approved and released, and this could cause additional frustration and confusion when billing.

\section{Creating Shared Payer and Provider Cost Savings}

Payers and providers anticipate that the adoption of biosimilars will offer a compelling savings opportunity and could be a strategy to reduce specialty drug spend overall; however, this is dependent on the ability to generate a magnitude of cost savings for the plan and the availability of adequately appropriate reimbursement for physicians. This also holds true for physicians who may feel that they will be missing out on potential revenue dollars generated by biosimilars, as there still is ambiguity surrounding what the cost savings will actually be.

Uncertainties Regarding Potential Savings. There is no consensus on the magnitude of potential savings that could be generated from biosimilar entrants, and all available estimates are highly variable. Therefore, as biosimilars emerge into the marketplace, it is imperative to manage cost-savings expectations. Express Scripts predicts that the United States could potentially save $\$ 250$ billion between 2014 and 2024 if 11 of the most likely biosimilars entered the marketplace. ${ }^{10}$ The U.S. Congressional Budget Office projects that there will be $\$ 25$ billion in reduced total expenditures on prescription drug budget from 2009 to 2018, which would be equivalent to $0.5 \%$ over that 10-year period. ${ }^{11}$ In 2014, Rand Corporation conducted an analysis that estimated biosimilars would result in a $\$ 44.2$ billion reduction in biologic spending between 2014 and 2024, which would equate to approximately $4 \%$ of total biologic spending over that time frame. ${ }^{12}$

Milliman, a consulting firm, evaluated 3 scenarios for biosimilars in order to assess potential employer savings. The scenarios were as follows ${ }^{13}$ :

1. Aggressive market penetration (30\%) with complete patient/physician acceptance, a 30\% discount, and a $\$ 50$ copay differential.

2. Fifteen percent market penetration, half of patients and physicians accepting their use, $20 \%$ biosimilar price discount, and $\$ 50$ copay differential.

3. Market penetration between $15 \%$ and $25 \%$ and price discount of $20 \%$ to $30 \%$, with both gradually increasing during the 5 years after approval. 
These scenarios are based on a 10,000-member commercial plan, and employer projected savings would be between $\$ 217,283$ and $\$ 635,925$ in $2019 .^{13}$ In 2019 , savings for a commercial plan would range from $2.6 \%$ to $7.6 \%$ of total drug spending and $0.3 \%$ to $0.8 \%$ of total health care spending. ${ }^{13}$

Payers and providers agree that the cost of a biosimilar is a major issue, as the cost is a major driver of coverage decisions. The potential for cost savings will vary across biologic classes based on sales, competition, and the timing of a biosimilar entering the market. Payers are also concerned that if they adopt a biosimilar, they would forfeit any available reference product rebates. If the product cost is high for a provider, it will discourage use of the product if they are not being reimbursed appropriately and in an expeditious fashion. From the payer perspective, there is a delicate balance between incentivizing physicians to utilize biosimilar products and sacrificing the potential savings.

\section{Potential Solutions}

\section{Provider Confidence in Biosimilar Education and Clinical Value}

Awareness and Education. The panel recommended that a series of webinars educating providers and their office staff about biosimilars would be helpful to increase understanding. Materials and tools should also be disseminated in order to support patient education on biosimilars. In addition, the panel felt that it would also be helpful to develop and deliver educational materials that are endorsed by sources providers trust, such as specialty societies and KOLs.

Provider-Focused Clinical Educational Programs. Health plans can invest in an educational campaign for providers; however, all stakeholders should cooperate in the education process. In addition, the entire health care community will have to find ways to collaborate through many educational vehicles and opportunities to include all key decision makers who will be involved. For example, a payer may have their own platform when educating providers, which could be unique according to the drug and disease state. Education needs to be provided to health plans and providers to develop a comfort level in order to drive utilization and increase patient acceptance. The educational component should focus on the biggest questions and concerns providers may have and topics most likely to inspire change, such as safety/efficacy information and regulatory guidelines and best practices.

Provider Involvement. The engagement of providers using responsive communication channels that help to gauge their attitudes and behaviors surrounding biosimilars will also help to gain insights that support messaging. With supportive care and acute therapies, it may be easier to transition the market share. With chronic therapies, providers and payers will have to work together to become comfortable with biosimilars before realizing the cost benefits associated with these products. Payers and providers are unsure if biosimilar therapy will begin with new patients, existing patients, or both. If providers choose to utilize biosimilars strictly for treatment-naïve patients, providers will need to identify new patients to initiate on a biosimilar product; this will lead to providers obtaining experience first-hand and then allow a comfort level in order to begin switching patients from the reference product to the biosimilar when appropriate. If providers choose to initiate biosimilar therapy on existing patients in addition to new patients, this will require additional education for existing patients who are being treated with the reference product. If these patients are already doing well on the reference product, they may question why a provider would switch therapies (e.g., cost, potential side effects). There could be some pushback from the patient in this circumstance, which solidifies why education is such a huge component pertaining to biosimilars.

Confidence in Biosimilar Clinical Value. The panel agreed that providers should have access to clinical trial data to ensure that there are no differences in toxicity or efficacy between the reference product and the biosimilar and also to be educated on properly reporting adverse events associated with biosimilars and other biologics. Providers want to be assured that the biosimilar manufacturing process is highly regulated in order to maintain safety and quality of the product and provide clinical performance in a consistent manner. In general, the panel agreed that if the FDA has approved the biosimilar product, most providers will be accepting of the biosimilar's equivalency to the reference product.

\section{Provider Confidence in Reimbursement for New Biosimilars}

Payer Communication with Provider Groups. Payers can start the process of engaging earlier rather than later with hospital systems and large group practices to start dialogue, determine the level of understanding, and assess what it would take them to get on board with collaboration. Payers can modify current information technology (IT) infrastructure to allow for seamless approval and reimbursement for miscellaneous biosimilar codes to promote earlier uptake of the biosimilar. Payers can also adjust physician fee schedules to encourage physicians to utilize lower-cost alternatives. The panel felt that the following examples are possible solutions to increase provider confidence in reimbursement, education, and access.

1. Create a provider-facing biosimilar portal.

a. Providers agree that the development of a portal would be helpful to their practice when billing for these agents in which a provider selects the patient and enters the product name and the J-code, dosing, and National Drug Code automatically populate. The biosimilar will be coded in a certain way in the system 
so that it will go to a specific queue so the health plan can evaluate the claim for immediate approval or payment or indicate that a decision will be made in an expeditious fashion.

2. Implement an immediately available campaign.

a. E-campaigns and provider updates sent from the payer to the provider to inform them of the technology change, training dates on the new technology, requests for training, and billing and coding associated with the biosimilar will be significant for awareness to avoid any administrative confusion with the provider.

3. Remove "speed bumps" for the biosimilar.

a. Removing administrative burden preferentially from biosimilars is another potential solution to decrease the financial burden and increase the adoption of biosimilars among providers. By streamlining the administrative process and ensuring providers are paid in a seamless and efficient fashion, better adoption of biosimilars can be expected. Basically, this can be done on the payer end, in which the payer selects the products in their systems that they will allow to be processed without any barriers blocking reimbursement to make sure providers are not receiving denials once they bill for a biosimilar. This option is only for select providers who the plan collaborates with and feels comfortable that they will not prescribe off-label; this is not for all physicians. It is the responsibility of the provider to engage with the payer to ensure that they have this capability prior to utilizing biosimilars. This essentially gives providers open access to the biosimilar.

Payer-Manufacturer Partnership. Biosimilar manufacturers should collaborate with payers in order to help payers implement utilization management techniques to promote the use of biosimilars under the medical benefit. Medical management can be implemented using a prior authorization process, fee schedule management, and the development of medical policies. Under the medical benefit, there is an opportunity for payers to drive utilization of biosimilars through the incorporation of management strategies, such as through a medical benefit prior authorization and utilization of the portal previously explained.

Medical policies do not have to be recreated in order to prefer a biosimilar; rather, they should give the provider an option to use the reference product or the biosimilar. The panel stated that all providers may not have this option because it is dependent on whether the health plan has a policy in place to cover the reference product and/or biosimilar. In addition, the panel stated that, in essence, provider behavior should match health plan behavior in that, when a health plan is developing a policy to cover or not to cover the biosimilar, the prescribing behavior should match that of the health plan.
Policy Development. Payers still had questions surrounding how to develop medical policies so that providers feel comfortable that they will be fairly reimbursed for utilizing the biosimilar product. In addition, there are questions regarding whether the development of a medical policy should apply only to patients who would be considered as new starts utilizing the biosimilar or if a medical policy applies to all potential patients. Payers feel they need to be careful with how biosimilar medical policies are drafted in order to avoid delaying or slowing the uptake of biosimilars. The panel recommended that, when crafting medical policies for supportive care products, consideration should be given to whether the policy could apply to new starts only in order to drive market share. The panel also stated that payers are concerned with whether providers will feel comfortable switching patients on chronic therapy to new biosimilar market entrants. Certain providers may be more hesitant and want to see trial data in order to make clinical judgments. Each therapeutic category needs to be evaluated separately in order to drive market share and optimize savings. Payers and providers should work together when evaluating each product and in the development of medical policies. Providers could provide additional insights as to what products they are comfortable with and the correlating clinical trial data, best practices, appropriate patients to initiate therapy for, etc. This serves as a foundation for payers and providers to actively engage with one another and to play a key role in the implementation of medical policies that makes sense for payers, providers, and patients.

\section{Creating Shared Payer and Provider Cost Savings}

Shared Savings. Payers can take the lead by sharing the savings associated with biosimilars with providers as a way to ensure they are bringing the greatest value to providers and patients. The panel stated that these shared savings can be managed through higher reimbursement to the providers utilizing biosimilar products. There is also a savings opportunity in the outpatient setting. Shared savings increases for outpatient physician practices and infusion centers can be used as a means to increase the uptake of biosimilars. Additionally, as we migrate from volume to value, biosimilar adoption could provide significant savings for accountable care organizations (ACOs)/shared savings and other new models and risk programs. The panel felt physicians should take the responsibility of articulating their comfort level with biosimilars, especially for patients who are new starts to a biosimilar product. This will help biosimilars to take effect with patients, as providers are sending the message that they are starting the patient with the best treatment and most cost-effective option. 
Focus on Accountable Care Organizations. A growing area in the U.S. health care marketplace that is perfectly structured to implement strategies designed to optimize the savings potential associated with biosimilars are ACOs or within current contractual arrangements between payers and providers and/or hospital systems that are based on shared savings opportunities. While there is an agreement among payers and providers that there needs to be some sort of shared savings, it is important that the generation of savings does not negatively affect patient care. The panel did agree that they did not want the potential of inadequate savings to the provider to negatively affect patient care if they felt that the patient would indeed benefit from the biosimilar but the physician did not prescribe the biosimilar due to the feeling that there are not enough shared savings involved.

Assess the Whole Spectrum of Savings Potential. When assessing the financial opportunity associated with biosimilar products, it is important to consider the whole spectrum with regard to the price point of the biosimilar compared to the reference product. It is important to consider the WAC of the biosimilar in comparison to the WAC, ASP, and plan's net price (which includes rebates and discounts for the reference product). This complete evaluation will help plans to fully understand the true savings potential. Health plans also feel that it would be helpful if biosimilar manufacturers could provide a shared savings model delineating the contrast in savings if adopted earlier versus later and/or other types of incentive models that address the complexities associated with biosimilar adoption. Additionally, to reduce the confusion associated with bundled ASP, time should be dedicated to educate providers on the billing, coding, and reimbursement process, aiming to properly explain the rules as to how biosimilars will be reimbursed.

\section{Future Implications for Health Plans and Providers}

While biologics have had a tremendous impact within health care, until recently, many of these biologics have not faced much competition. With the introduction of biosimilars into an area that has had little to no competition, the panel felt biosimilars have the opportunity to offer more choices at more affordable prices. Payers and providers agree that if the savings exist with biosimilars, depending on benefit design, the money saved can be used in other patient-centric ways, such as lower member premiums and copayments. As more biosimilars are approved, this will create competition that can cause these products to thrive. Although payers have a great opportunity for cost savings generated by increased competition, they also face a significant risk if they are unable to optimize the value potential of lower-cost options.

Payers can start the process of engaging earlier rather than later with hospital systems and large group practices to start dialogue and determine their level of understanding and what it would take them to get on board with collaboration, as uptake is going to differ between integrated health systems versus traditional health systems. Payers can modify current IT infrastructure to allow for seamless approval and reimbursement for miscellaneous biosimilar codes to promote earlier uptake of biosimilars. Providers and payers will have to make the decision on the best IT infrastructure that will align with payer policies when billing and coding for biosimilars; they will also have to ensure that the physician understands and receives the appropriate reimbursement and that patients will be financially liable for the correct amounts per their benefit designs. Physician feedback on this infrastructure is critical, as billing and coding must be done in a seamless fashion so that this allows increased comfort levels with biosimilar uptake. As all biosimilars will require a modifier when billing and coding, there should be some thought as to how to queue biosimilars within the IT system so that payers receive the request in an immediate fashion in order to grant a prior authorization and guarantee payment. Payers will have to take responsibility for educating physician offices on how to use the IT system. Payers can also adjust physician fee schedules to incentivize physicians to utilize low-cost alternatives.

If a manufacturer cannot supply enough of a biosimilar for providers and patients, this could cause a decrease in utilization and a lack of confidence in the capability of the manufacturer. This is an ongoing problem with non-biosimilar products, and providers face shortages of one or more drugs on a regular basis. The members of the panel stated that based on their experience, shortages can adversely affect drug therapy, compromise or delay medical procedures, and result in medication errors leading to an increase of adverse events. According to the FDA in 2015, there were many drugs listed in short supply. ${ }^{14}$ Manufacturers should be prepared for the potential demand in order to reduce the risk of shortages and then actively notify providers of potential shortages. Manufacturers should also be proactive and reduce the risk of drug shortages and have plans in place to shorten recovery times in the event of a drug shortage.

The panel felt biosimilar manufacturers must be diligent surrounding the regulatory issues that remain. These include guidance surrounding naming, extrapolation of indications, and interchangeability. Manufacturers will need to be proactive in developing strategies surrounding these issues in order to remain competitive. For example, if all indications are not extrapolated, manufacturers need to be prepared to handle this situation in addition to determining, in real time, what additional clinical trials they may have to conduct or what other scientific justification they will need in order to address this issue.

The panel also expressed that biosimilar manufacturers should consider the pricing implications for payers and providers and try to make an effort to ensure that everyone is offered 
an equal opportunity to realize cost savings. Both payers and providers understand the current economics associated with the utilization of reference products and potentially biosimilars; as each biosimilar product enters the market, each product must be reviewed independently by payers. However, payers should utilize the opinions from leading prescribers within the associated geographies of each payer to ensure everyone's objectives are being met economically and clinically. Even though there are still challenges and unanswered questions, there are opportunities for payers and providers to share in the economic benefit of future products.

The emerging biosimilars market not only presents an opportunity for pharmaceutical manufacturers but for health plans, providers, and patients. Biosimilars have the potential to save the U.S. health care system billions of dollars over the next few decades. However, it is imperative that health plans and providers collaborate and are accepting of biosimilars in order to increase acceptance and adoption. Without this collaboration or alignment of incentives, biosimilars may struggle to attain a meaningful market share, therefore limiting their cost-savings potential. This may also have a negative impact on the future of biosimilar entrants. Pharmaceutical manufacturers will be reluctant to invest in the development of biosimilar products if a return on that investment is unlikely. This highlights the need for payers and providers to think creatively about how mutually beneficial collaborations could be structured to promote the successful adoption of biosimilars and generate cost savings for the health care system.

\section{Authors}

CHRONIS H. MANOLIS, RPh, UPMC Health Plan, Pittsburgh, Pennsylvania; KIRAN RAJASENAN, MD, University of Pittsburgh Medical Center, Pittsburgh, Pennsylvania; WILLIAM HARWIN, MD, Florida Cancer Specialists \& Research Institute, Fort Myers, Florida; and SCOTT MCCLELLAND, RPh, Florida Blue, Jacksonville, Florida. MARIA LOPES, MD, and CAROLYN FARNUM, BS, CDMI/Magellan Rx Management, Newport, Rhode Island.

\section{REFERENCES}

1. U.S. Food and Drug Administration. FDA News Release. FDA approves first biosimilar product Zarxio. March 6, 2015. Available at: http://www. fda.gov/NewsEvents/Newsroom/PressAnnouncements/ucm436648.htm. Accessed August 10, 2016.
2. Gordon E. FDA decision signals new competition for some of the costliest drugs. NPR. March 10, 2015. Available at: http://www.npr.org/sections/ health-shots/2015/03/10/388668910/fda-decision-signals-new-competitionfor-some-of-the-costliest-drugs. Accessed August 10, 2016.

3. Miller S. Infographic: Two biosimilars to save $\$ 22.7$ billion. Express Scripts. December 4, 2014. Available at: http://lab.express-scripts.com/ insights/drug-options/infographic-two-biosimilars-to-save-227-billion. Accessed August 10, 2016.

4. Polite B, Ward J, Cox J, Morton R, Hennessy J, Page R, Conti R. Payment for oncolytics in the United States: a history of buy and bill proposals for reform. J Oncol Pract. 2014. Available at: http://jop.ascopubs.org/content/10/6/357.full. Accessed August 10, 2016.

5. Micromedex Solutions. Truven Health Analytics. RED BOOK Online. August 10, 2016.

6. Centers for Medicare \& Medicaid Services. 2016 ASP Drug Pricing Files. Available at: https://www.cms.gov/apps/ama/license.asp?file=/ McrPartBDrugAvgSalesPrice/downloads/2016-January-ASP-Pricing-File.zip. Accessed August 10, 2016.

7. Quantia. A roadmap for engaging physicians in the biosimilars discussion. August 2015. Available at: http://www.businesswire.com/news/ home/20150818005839/en/Quantia-Report-Reveals-Physician-AttitudesBiosimilars. Accessed August 10, 2016.

8. Centers for Medicare $\&$ Medicaid Services. Food and Drug Administration approval of first biosimilar product. MLN Matters No. SE 1509. 2014. Available at: https://www.cms.gov/Outreach-and-Education/ Medicare-Learning-Network-MLN/MLNMattersArticles/Downloads/SE1509. pdf. Accessed August 10, 2016

9. Centers for Medicare \& Medicaid Services. Part B biosimilar biological product payment and required modifiers. December 23, 2015. Available at: https://www.cms.gov/Medicare/Medicare-Fee-for-Service-Part-BDrugs/McrPartBDrugAvgSalesPrice/Part-B-Biosimilar-Biological-ProductPayment.html. Accessed 2007. June 25, 2008. Available at: https:// webcache.googleusercontent.com/search?q=cache:ChskpZj9JaIJ:https:// www.cbo.gov/sites/default/files/cbofiles/ftpdocs/94xx/doc9496/s1695. $\mathrm{pdf}+\& \mathrm{~cd}=1 \& \mathrm{hl}=\mathrm{en} \& \mathrm{ct}=\mathrm{clnk} \& \mathrm{gl}=\mathrm{us}$. Accessed August 19, 2016.

10. Miller S. The $\$ 250$ billion potential of biosimilars. Express Scripts. April 2013. Available at: http://lab.express-scripts.com/insights/industry-updates/ the-\$250-billion-potential-of-biosimilars. Accessed August 10, 2016.

11. Congressional Budget Office. Cost estimate: S. 1695 Biologics Price Competition and Innovation Act of 2007. June 25, 2008. Available at: https://www.cbo.gov/sites/default/files/cbofiles/ftpdocs/94xx/doc9496/ s1695.pdf. Accessed August 19, 2016.

12. Singh S, Bagnato K. The economic implications of biosimilars. Am J Manag Care. 2015;21(16 Suppl):s331-40.

13. Milliman. Understanding biosimilars and projecting the cost savings to employers-update. Milliman White Paper. June 29, 2015. Available at: http:// us.milliman.com/uploadedFiles/insight/2015/understanding-biosimilars.pdf. Accessed August 10, 2016.

14. U.S. Food and Drug Administration. FDA drug shortages. Available at: http://www.accessdata.fda.gov/scripts/drugshortages/default.cfm. Accessed August 10, 2016. 


\section{Supplement}

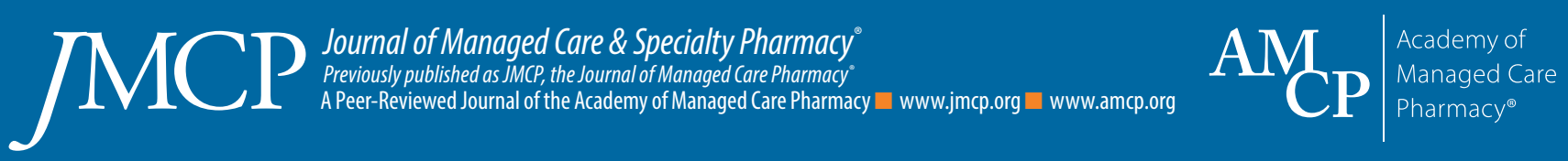

